\title{
Expected Cost of Equity and the Expected Risk Premium in the UK
}

\author{
Alan Gregory \\ XFi Centre for Finance and Investment, University of Exeter \\ Business School
}

This version: October 2010

Discussion Paper No: 10/08

Draft: Please do not quote without permission

I am grateful to George Bulkley, Mark Freeman, Sudi Sudarsanam and Ian Tonks for helpful comments on earlier versions of this paper. The usual disclaimers with respect to errors and omissions apply. 


\section{Expected Cost of Equity and the Expected Risk Premium in the UK}

In this paper, it is argued that previous estimates of the expected cost of equity and the expected arithmetic risk premium in the UK show a degree of upward bias. Given the importance of the risk premium in regulatory cost of capital in the UK, this has important policy implications. There are three reasons why previous estimates could be upward biased. The first two arise from the comparison of estimates of the realised returns on Government Bond ("Gilt") to realised and expected returns on equities. These estimates are frequently used to infer a risk premium relative to either the current yield on index-linked gilts or an "adjusted" current yield measure. This is incorrect on two counts; first, inconsistent estimates of the risk free rate are implied on the right hand side of the CAPM (Jenkinson, 1993); second, they compare realised returns from a bond which carried inflation risk with realised and expected returns from equities which may be expected to have at least some protection from inflation risk. The third, and most important, source of bias arises from uplifts to expected returns. If markets exhibit "excess volatility" (Shiller 1981), or if part of the historical return arises because of revisions to expected future cash flows, then estimates of variance derived from historical returns or price growth must be used with great care when uplifting average expected returns to derive simple discount rates. Adjusting expected returns for the effect of such biases leads to lower expected cost of equity and risk premia than those that are typically quoted. 


\section{Expected Cost of Equity and the Expected Risk Premium in the UK}

\section{Introduction}

A focus of some recent work on the equity risk premium has been the resolution of the risk premium puzzle identified by Mehra and Prescott (1985). Campbell (1999), and Dimson, Marsh and Staunton (2002, 2006, 2007) show that the puzzle exists in the international data as well as the US data. The observed historical premia over both Treasury Bills and Government Bonds are too high to be consistent with any plausible degree of relative risk aversion on the part of investors. Attempts to resolve the problem include modifications to the theoretical models that determine the coefficient of relative risk aversion, a useful review of which is in Cochrane (Chapter 21, 2001), and analyses that examine the effect of revisions in cash flow expectations on the historically observed risk premium (Fama and French, 2002; Dimson et al, 2006). Similar to Fama and French (2002), this paper contributes to the latter body of work by estimating the UK risk premium based upon rational historical expectations of the ex ante equity return and risk premium. As in Dimson et al (2006) and Vivian (2007) a dividend growth ("Gordon's growth") model is used, but the estimates are constructed by incorporating growth terms based both on dividend growth and earnings growth. For completeness the implied cost of capital from the forward earnings growth (FEG) model of Ohlson and Juettner-Nauroth (2005) model. This requires estimates of both short run and long run earnings growth, and for the latter estimates are made using the long run average earnings estimates using the approach on Robert Shiller's website. ${ }^{1}$ Thus this study should be viewed as complimentary to that of Dimson et al (2006) and Vivian (2007) in these respects. ${ }^{2}$

A further puzzle that has been observed in past equity prices is the "excess volatility puzzle" (Campbell, 1996; Campbell and Shiller, 1988). Historically, the volatility of returns seems too high to be reconciled with the observed volatilities in dividend and consumption growth, and this volatility exacerbates the problem of explaining the observed equity risk premium as it implies a degree of mean reversion in stock prices. Furthermore, as Cochrane (2001, p. 460) points out, these standard deviations are so

\footnotetext{
${ }^{1}$ See: http://www.econ.yale.edu/ shiller/data/ie_data.xls

2 The incorporation of an earnings growth estimate comes at a cost. Whilst Dimson et al (2006) provide dividend growth estimates back to 1900 , from the data used in this study it is only possible to obtain historical series back as far as 1924 for dividends and 1927 for equities.
} 
high that they imply a large amount of uncertainty about the true equity risk premium, a fact that he describes as a "surprisingly underappreciated problem".

Whilst it is widely recognised that revisions in cash flow expectations have implications for the estimation of the ex ante risk premium, there seems to be little explicit recognition of the importance of the excess volatility studies for this ex ante premium $^{3}$. One line of argument is that if the expected premium is not serially correlated, then the correct approach to estimating the annual discount rate for equities is to use the arithmetic risk premium. However, there are three caveats here. First, whilst advocating the use of expected simple one period returns in discounting, Fama (1996) highlights the fact that discounting forecast net cash flows by such discount rates implies that the distribution of these cash flows more than one period ahead are right-skewed. Second, Blume (1974) shows that the arithmetic average of an historical series of data gives rise to an upward biased estimate of the $N$-period return, whilst the geometric average is downward biased. He proposes an horizonweighted average of the arithmetic and geometric average returns to deal with this problem. Third, if there is autocorrelation in past returns, then it does not follow that the arithmetic average will give a reliable measure of simple one period ahead returns, although in a simulation study Indro and Lee (1997) show that Blume's (1974) recommendation of an horizon-weighted average exhibits the least bias compared to alternative estimators. In related work, Cooper (1996) shows that in the presence of estimation error and serial dependence in returns, the corrected discount rate is closer to the arithmetic mean of the historical series than the geometric mean. However, Cooper (1996, p.165) acknowledges that "it may be that the correct model of returns is more complex than that analysed here". One of the purposes of this paper is to attempt to estimate just such an alternative model of expected returns.

If expected returns are lognormally distrubuted, from Jensen's inequality the arithmetic average risk premium should be approximately the geometric average risk premium plus half the variance. Dimson et al (2002, p.193) use a $16 \%$ estimate of projected market volatility when moving from geometric to arithmetic averages,

\footnotetext{
${ }^{3}$ An exception is Vivian (2007, p. 1508) who notes "An important advantage of the UK dividend growth model is that it does provide a more precise estimate of the equity premium since the variance of the dividend model is considerably smaller than that generated by average returns especially since $1950 "$
} 
equivalent to an uplift of $1.3 \%$. Fama and French (2002) argue that price growth is more volatile than dividend growth, and so any estimate of the ex ante risk premium needs to be adjusted to allow for this. In general, if such adjustments are formed on the basis of historically measured variances a problem that arises is that historically observed price growth embeds both the effects of unanticipated cash flow growth and any "excess volatility" resulting from irrational pricing movements. Unless one expects both of these effects to continue into the future, or alternatively rejects the notion of "excess volatility" altogether, any historical estimate of price growth variability will be an over-estimate of the expected variance. As the volatility from the historically estimated long run dividend growth series is considerably lower than either the volatility of past stock prices or contemporaneous market volatility estimates, it can be argued that any estimates of the ex ante arithmetic premium derived by adjusting dividend growth model estimates for observed price volatility are over-estimates. This line of argument also depends on the interpretation placed on such forward estimates. Fama and French (2002, p.638) regard the average of such estimates as an estimate of the unconditional expected stock return. By contrast, Claus and Thomas (2001, p.1630) regard their ex ante estimates as conditional on the information available in any one year, and specifically note "we do not consider an unconditional equity premium toward which those conditional premia might gravitate in the long run". This difference in interpretation is of critical importance in identifying the correct estimate of the ex ante simple annual return, as under the Claus and Thomas (2001) interpretation no adjustment would need to be made to the mean estimated premium, in contrast to the Fama and French (2002) recommendation. Although the main focus is on the arithmetic average return, an added benefit of a more precise (i.e. less volatile) estimate of any equity return or risk premium is that it helps in addressing the "surprisingly underappreciated problem" that Cochrane (2001) highlights. $^{4}$

The equity risk premium in the UK is of central importance to regulators, who make use of it both in setting utility prices and in market investigations, to investors and the

\footnotetext{
${ }^{4}$ It should be noted that Dimson et al (2006) conducts a world-wide decomposition analysis using geometric returns and is altogether less strong in advocating the use of arithmetic averages, noting that "For those who focus on the arithmetic mean" the world arithmetic average premium is $1.3 \%$ higher than its geometric counterpart, although in the concluding paragraph a geometric world risk premium of 3 to $3.5 \%$ is used to suggest an arithmetic premium of $4.5 \%$ to $5 \%$.
} 
investment community, and to corporate finance departments. Precisely because of the UK regulatory regime, an accurate estimate of the risk premium is of particular concern in this country. In a recent report for Ofgem, Wright et al (2006) argued in favour of an uplift of $2 \%$ in obtaining the arithmetic risk premium from the the geometric risk premium on the grounds that such an uplift is "conservative". Others might regard such an uplift as being not necessarily in the interests of consumers. In addition, regulators appear to impart two further sources of bias in the estimation of the risk premium. The reason is that regulators and their advisors have typically estimated a real premium relative to either government bonds ("Gilts") or Treasury Bills, and then added this to a contemporaneous estimate of the real risk free rate. A recent example can be found in the recent NERA review for the latest water industry 2009 price review $^{5}$, where they argue for a $5.4 \%$ risk premium based largely upon long run arithmetic averages and add that to a $2.5 \%$ estimated risk free rate of return. There are two problems with this line of reasoning. The first goes back to Jenkinson (1993) who argues that there is only one risk free rate in the Capital Asset Pricing Model (CAPM). As such, it is inappropriate to incorporate an equity risk premium derived using one risk free rate, the historical figure, in the CAPM if the first term on the right hand side (RHS) uses a different estimate of the risk free rate, the current rate. This bias suggests that either historical estimates of the risk free rate should be used throughout, or that the appropriate term to incorporate on the RHS of the CAPM is an estimate of the expected return on equities, from which the current risk free rate is deducted. In a similar vein, Wright et al $(2003)^{6}$ argue against the separate estimation of the risk free rate and an equity risk premium on the grounds that estimates of the return on equities exhibit more stability than estimates of the equity risk premium.

The second bias in the current regulatory approach is rather more subtle. The problem here, in the case of the analysis of the historical expected equity premium, is that there is a danger of comparing expected returns on equities, which may be to some degree insulated from inflation risk, with ex post realised returns on bonds, which are not. The appropriate approach would be to compare the ex ante estimate of real equity returns with the ex ante estimate of real gilt returns, using common

\footnotetext{
${ }^{5}$ See: http://www.nera.com/extImage/PUB_Cost_of_Capital_PR09_Jan2009_update.pdf

${ }^{6}$ Sometimes referred to as the "Smithers Report".
} 
estimates of inflation. This implies using yearly estimates of government bond yields to redemption, rather than realised returns. Such an analysis, in nominal terms, is undertaken by Claus and Thomas (2001), but this contrasts with the approach used in studies of historical investment returns (e.g. Barclays Capital (2007), Dimson et al (2007)) which typically take the risk premium over gilts as the realised real equity return minus the realised real bond return. This approach is not wrong if one is concerned with the historical returns actually earned by investors, but it will give a misleading estimate if combined with an inflation-protected index linked gilt (ILG) yield to give an estimate of the current risk premium.

A related potential bias is the long-standing insistence by regulators that "market distortions" mean the observed yield on ILGs may be unreliable, and so an uplift is required. This can either be because of "Bayesian updating" arguments to the risk free rate, cited by Europe Economics (2009) on behalf of Ofwat, ${ }^{7}$ or because the regulator thinks the market rate itself may be unreliable. For example, the latest relevant Competition Commission report on Bristol Water observes " current indexlinked yields are about 1 per cent. As they may still be affected by market distortions we considered that a range of 1 to 2 per cent for the risk-free rate was appropriate" (Competition Commission, 2010, p.65). However, this is not in itself wrong if regulators recognise that this figure should be compared to expected return on equities, as indeed the $\mathrm{CC}$ does. The danger is that a regulator may uplift the risk free rate and then add to that an estimated risk premium, a path that appears to have been followed by Ofwat in its "PR09" price determination. However, regulators are changing tack, and the CC's recent approach avoids any bias by explicitly estimating the cost of equity directly, and then deducting the estimated risk free rate. This approach was also followed in the Stansted Airport inquiry. Whilst the result gives a small advantage to firms with betas that are less than unity, it is an approach that is unbiased and theoretically consistent.

Finally, outside the regulatory sector there is evidence, albeit dated, from Gregory, Rutterford and Zaman (1999) that suggests the corporate sector may be making errors in estimating cost of capital. Intriguingly, though, the same study (which specifically

\footnotetext{
${ }^{7}$ See: http://www.ofwat.gov.uk/pricereview/pr09phase3/rpt_com_20091126fdcoc.pdf
} 
compares industry perception with those of the City) suggests that half of their investor group used far lower estimates of cost of capital than the industry group. For this group of investors the risk premia being applied were considerably lower than those that have been used by regulators.

The purpose of this paper is to examine the above sources of potential bias in estimates of the UK ex ante equity cost of capital and of the risk premium, and to calculate bias-free estimates of these series depending on alternative beliefs concerning price volatility. As these potential biases are positive and significant, the paper has policy implications for UK regulators, and for others with an interest in the UK equity cost of capital. The paper proceeds by describing the research method and data used in the study, and then describes the results of the analysis.

\section{Method and Data}

The research method is conceptually extremely simple, and relies on the fact that in rational markets, the price of any equity must be the present value of the future dividend stream. Given the interest is in the expected return, $R_{m}$, on a market-wide portfolio, expressing prices in terms of an expected forward real dividend yield on the market, and assuming constant real growth in perpetuity, implies that expected returns are given by:

$$
E_{t}\left(R_{m}\right)=\frac{E_{t} \boldsymbol{Q}_{t+1}}{P_{t}}+E_{t} \boldsymbol{g}_{t}^{-}
$$

where $D_{t+1}$ is the real dividend one period hence, and $g_{t}$ is the long run real growth in prices. Provided the real dividend yield is stationary, long run real price growth will be equivalent to the long run real growth in dividends. The problem is how to estimate expectations. Initially, as in Fama and French (2002, hereafter FF), the assumption is that real dividend growth $\left(G D_{t}\right)$ is simply a function of the most recent period's real dividend growth, where real dividends are defined by $d_{t \cdot}\left(R P I_{t-1} / R P I_{t}\right)$, $R P I_{t}$ is the level of the retail price index at time $\mathrm{t}$, and $d_{t}$ is the nominal dividend at time t, and $G D_{t}=\left(d_{t} / d_{t-1}\right) .\left(R P I_{t-1} / R P I_{t}\right)$. Given this simplifying assumption concerning dividend growth, we can estimate the historical series of expectations as: 


$$
\bar{R}_{m, t}=\frac{\bar{D}_{t}}{P_{t-1}}+\bar{G} D_{t}
$$

There are alternative methods of estimating growth. The first, possibly more applicable to the US than the UK, recognises that that if there is a trend towards the use of share buybacks, a better estimate of long run growth in prices may be the earnings growth rather than dividend growth. ${ }^{8}$ As in $\mathrm{FF}^{9}$, this estimate of real price growth, $G Y_{t}$, is given by $\left(y_{t} / y_{t-1}\right) .\left(R P I_{t-1} / R P I_{t}\right)$, where $y_{t}$ is the nominal earnings figure in year $t$. However, there is no particular reason to suppose that investors naively form growth expectations each year on the basis of the last year's dividend or earnings growth, as assumed by FF. Alternative specifications are possible, so for example one could use rolling multi-year average estimates of dividend or earnings growth as a proxy for growth over the trade cycle. Dimson et al (2002) use the full historical run of data in any year to give an estimate of expected growth, although their approach has the different objective of calculating unexpected dividend growth. Vivian (2007) shows that the both short run and longer run (5 year) dividend growth appears to be predictable in the 1965-2004 period, implying that an econometric model of dividend growth may be a possibility, although he shows that out-of-sample a long run average has superior predictive power. These alternatives are estimated later, but the important point is that such estimates of future return will generally exhibit lower volatility than estimates formed using naïve annual revisions. As such, the standard conclusions drawn from the basic estimates made in this paper may be aggressive in terms of their implications for arithmetic average returns. With longerrun estimates of dividend growth, the standard deviation of the $G D_{t}$ term would be depressed leading to a smaller standard deviation of expected equity returns. Indeed, we show this is exactly the case when we estimate a time-varying dividend yield approach.

\footnotetext{
${ }^{8}$ Note that an alternative approach to the problem of share buybacks is the use of a share-buyback adjusted dividend yield, as in Vivian (2007).

${ }^{9}$ Fama and French (2002) note that any variable that is cointegrated with stock price can be used to derive (1), so that if firms move away from dividend payout, implying that the dividend-price ratio is non-stationary, forming a growth expectation on the basis of earnings growth will be valid provided that the real earnings yield is stationary.
} 
There are alternative approaches to estimating cost of equity than the use of a dividend discount model. Claus and Thomas (2001) prefer a residual income approach, which they claim offer advantages over the dividend discount model and "make better use of available information". Whilst the Claus and Thomas results are useful (they report a mean risk premium over 10-year government bond rates of $3.4 \%$ for the US and $2.8 \%$ for the UK), their argument in favour of the residual income model rather than the dividend discount model is flawed. Properly applied, with consistent assumption, one is bound to get the same answer from the residual income model as from the dividend discount model (Lundholm and O'Keefe, 2001). The differences between the DDM and RI analyses in their paper come about solely as a result of inconsistent assumptions in the growth rates assumed, rather than the model application per se. A weakness of the RI model is that it requires estimates of book value to be available, and additionally requires that accounting income is measured on a "clean surplus" basis. Observing book values over the long term, which is what is required here, is extremely onerous. Furthermore, until very recently UK accounting has made use of "dirty surplus" accounting, particularly with regard to goodwill accounting and asset revaluation. The FEG model has the considerable advantage that it does not require accounting to be "clean surplus" (Ohlson and JuettnerNauroth, 2005 p. 353). In its simplified two period growth form, the authors show that the model can be solved for an implied cost of capital. Expressed in terms of the notation used above, the authors show that

$$
\begin{aligned}
& R_{m, t}={ }_{A}+\sqrt{A^{2}+\frac{y_{t}}{P_{t-1}} \times\left(\frac{y_{t+1}-y_{t}}{y_{t}}-G Y_{t}^{L}\right)} \\
& \text { Where } A_{t}=0.5 \sqrt{G Y_{t}^{L}+\frac{D_{t}}{P_{t-1}}}
\end{aligned}
$$

and $G Y_{t}^{L}$ is an estimate of long term earnings growth made at time t.

As the focus of this paper is real returns, real dividend growth and price gains in any year are deflated by realised inflation (as measured by the retail price index) over the year. Monthly data are available for UK prices from 1915 onwards. Besides the equity data, returns on Treasury Bills, and Yield to Redemption data on UK Government Gilts are required. Consistent with the method used to estimate real 
future dividend, price and earnings growth, estimates of the expected real yield to redemption figures are derived by assuming that the past year's realised inflation is an unbiased estimator of the expected future inflation rate.

To estimate the dividend, earnings and price series requires long run market wide data. Dimson et al (2006) use their own estimates for the largest 100 UK companies for the early years of their sample, in contrast to with the Barclays Capital (2007) study which uses the thirty largest companies. In this study, the data source of earnings, price and dividend information for the early years (pre the formation of the FT All Share Index) is the Global Financial Data (GFD) database. ${ }^{10}$ GFD is also used as the source of data for early gilt yields, prior to long run bond yields being available on Datastream. The early gilt yields are based on Consol yields. GFD is also the source of inflation data prior to the UK retail price index being available on either Datastream or from the Office of National Statistics. It is important to emphasise that GFD has been selected as the descriptions of the data indicate that it is more widely based than the Barclays Capital data. ${ }^{11}$ Real dividends payable to investors are estimated as the simple 12 month average of the monthly dividend yields multiplied by the monthly equity price index, appropriately deflated by the RPI. In a similar fashion, earnings are calculated as the simple 12 month average of the monthly earnings yield, appropriately deflated. The annual estimates the real dividend and real earnings yields are illustrated in Figure 1.

To estimate long-run earnings growth an approach identical to that employed by Robert Shiller ${ }^{12}$ is employed, namely a rolling average of the ten year real earnings on the index is calculated. This also allows the calculation of a long run average 10 year trailing PE (PE10) to be calculated. In principle, one can estimate the implied cost of capital on a rolling basis from (3) above. Unfortunately, the formula breaks down under circumstances when short run earnings growth is smaller than long run earnings growth by a sufficient margin to render the term under the square root sign in (3) above negative. In such circumstances the choice is either to artificially constrain short run earnings growth, or to conclude that a cost of capital cannot be calculated

\footnotetext{
${ }^{10}$ Dimson et al (2006) use this same database as their source for the Canadian market. A full description of the data used by GFD can be found in Appendix 1.

${ }^{11}$ Although it should be noted that gilt, Treasury Bill and inflation data are similar.

${ }^{12}$ See footnote 1 .
} 
for some years. Neither alternative is terribly appealing, particularly as the latter implies ignoring observations where economic circumstances are likely to be adverse. So instead, the model is employed here only in relation to the entire run of data.

Finally, we employ regression models to estimate short run dividend growth. We show that there is evidence that short run dividend (and to a lesser extent earnings) growth can be forecast, particularly at the one year horizon. We then employ those growth estimates in a simple re-statement of (1) to directly estimate the expected dividend one period hence. We combine this with a rolling long run average estimate of the dividend (or earnings) growth to provide an alternative estimate of expected returns.

\section{Results}

\section{Historical returns}

We start with the analysis of historically estimated ex ante returns, which are reported in Table 1. The average real dividend yield $\left(\mathrm{D}_{\mathrm{t}} / \mathrm{P}_{\mathrm{t}-1}\right)$ of $4.58 \%$ is very close to the long run average real dividend yield of $4.7 \%$ recorded by FF, although the UK does not see the systematic decline in the average ratio reported in FF. The arithmetic average long run real growth in dividends $\left(\mathrm{GD}_{\mathrm{t}}\right)$ is $1.21 \%$, less than the FF US figure of $2.08 \%$. The geometric average of this dividend growth, reported in the bottom panels of Table 1, is $0.9 \%$, higher than the Dimson et al (2006) UK growth estimate for 1900-2005 of 0.61\%. To understand the difference in these estimates, we can use the detailed year-by-year breakdown of dividend income provided by Barclays Capital (2007), whilst recognising that these Barclays Capital data are based on a smaller universe of the thirty largest UK stocks. Their data paints a gloomier picture of UK growth than Dimson et al, with a very small decline in real dividends over the whole period (Figure 88, Barclays Capital 2007). However, this is largely driven by a fall of real dividend income of $86 \%$ from 1900 to $1919 .{ }^{13}$ The Barclays Capital implied real dividend growth over the period 1925-2006 is approximately $1.2 \%$ p.a.. Dimson et al

\footnotetext{
${ }^{13}$ I am grateful to Tim Bond at Barclays Capital for the following response to a query on the dividend income index: "On the start point, dividends in our sample indeed fell steeply in the first year or so. That reflects the usual impact of changes in constituents and changes in dividends. Then WW1 intervenes, which has a major impact on div policy amongst British companies. The methodology we used to construct the index is described in the study and it does not change over this period, so it reflects what was going on in the 30 largest capitalised stocks over this period."
} 
(2005, Ch. 3) have a useful international analysis on the relationship between dividend growth and GDP growth, showing that dividends lag substantially behind GDP growth in all the countries studied. Their World figure for real dividend growth was $0.64 \%$, compared to real GDP growth of $3.22 \%$, and real per capita GDP growth of $2.24 \%$ (Dimson et al, 2002, Table 12).

Over the period for which earnings data are available (1927 on, so allowing growth estimates to be made for the year 1928 on), Table 1 shows that the arithmetic average UK earnings growth $\left(\mathrm{GY}_{\mathrm{t}}\right)$ is $1.22 \%$, with a geometric average of only $0.39 \%$. The fact that arithmetic average earnings growth and dividend growth are broadly similar over the long run lends some comfort to the use of the conventional dividend growth model in the UK, as it suggests that share buybacks are not a material problem. Furthermore, since 1951 geometric real dividend growth (0.9\%) has been considerably higher than real earnings growth $(0.39 \%)$. This contrasts sharply with the US picture of FF, where real geometric earnings growth since 1951 has been $1.89 \%$, over double the geometric growth in real dividends of $0.92 \%$. A contributory factor here has been the serious decline in earnings during the current recession, and the fact that aggregate dividends have fallen by less than aggregate earnings. Nonetheless, the arithmetic averages show that since 1975 real earnings have grown at a higher average rate than dividends $(2.59 \%$ average earnings growth compared to $2.08 \%$ average dividend growth). As would be expected, earnings growth is more volatile than dividend growth and the standard deviations of the annual values show that earnings growth has a standard deviation of $12.65 \%$ over the whole period compared to a standard deviation of $7.92 \%$ for dividend growth. Similar to the US estimates of FF, the volatility of earnings growth is nonetheless lower than the volatility of price growth. Whilst the long run geometric mean of real price growth, at $1.2 \%$, is reasonably close to the dividend growth rate, and about $0.81 \%$ higher than the earnings growth, the long run arithmetic mean of price growth is $3.24 \%$ p.a.. The standard deviation of annual price growth, at $20.14 \%$ is far in excess of the standard deviations of earnings growth or dividend growth. The time series of these estimates are illustrated in Figure 2.

We now use these dividend and earnings growth estimates to calculate the implied expected returns on equity, using model (1) above with growth estimates using either 
the dividend growth series ([2] above) or the earnings growth as an estimate of the growth in dividends. Recall that in the first instance we naively assume that investors project forward using just their latest experience of real growth, and so our estimates are likely to be quite volatile ones. Such naïve projections give the estimates in columns 7 and 8 of Table 1 . The mean historical expected real return on equities derived from the dividend growth model, $R D_{t}$, is $5.79 \%$. The estimate is remarkably stable over the 1925-1950 and 1951-2009 sub-periods analysed (5.96\% and 5.72\% respectively), but the 1975 to 2009 average is higher at $6.25 \%$, reflecting the more rapid rise in real dividends over that period (arithmetic average 2.08\%). Although the overall $R D_{t}$ estimate is below the $1872-2000 \mathrm{FF}$ US estimate of $6.78 \%$, the 19512009 figure of $5.72 \%$ exceeds the FF 1951-2000 expected return of 4.74\%. However, the findings for the UK are similar to those for the US in one critical respect. FF contrast the observed total real shareholder return on the US market of $8.81 \%$ with their expected return of $6.78 \%$, noting that the difference is particularly acute in the 1951-2000 period (9.62\% realised versus $4.74 \%$ expected). For the UK, the arithmetic average realised real return, $R_{t}$, for the full period of $8.14 \%$ contrasts with a $5.79 \% R D_{t}$ figure $^{14}$. As in the US, the 1951-2006 period is the driver of the difference between realised and expected real returns, with average returns of $9.12 \%$ and $5.72 \%$ respectively.

When expected price growth is estimated from earnings growth, there is only a small impact on UK expected returns, in contrast to the FF study. The resulting estimates of expected returns resulting from assuming growth is equal to earnings growth gives a mean $R Y_{t}$ of $5.8 \%$, only $0.01 \%$ greater than the $5.79 \% R D_{t}$ estimate. In the individual sub-periods, differences do arise but these are primarily due to the volatility of earnings. Whereas the expected return for the dividend growth model varies from a low of $5 \%(1951-75)$ to a high of $6.25 \%$ (1975-2009), the figures for the earnings growth model range from $4.01 \%$ to $6.76 \%$ for the same two sub-periods. These contrast with the arithmetic average of the realised real return on the market for these two sub-periods being $9.29 \%$ and $8.99 \%$ respectively. It is again worth remembering that the volatility of the dividend and earnings estimates, modest as they may be compared to the volatility of the realised returns, is in part attributable to the

\footnotetext{
${ }^{14}$ Note that the full period geometric average realised return is $5.78 \%$ which contrasts with the Dimson et al (2007) geometric average of 5.5\%. This simply reflects the shorter period of this study.
} 
assumption that investors naively assume that the last year's realised real growth in dividends or earnings is indicative of future long run growth. We later relax this assumption of investor naivety by explicitly modelling expectations of short run and long run dividend growth, showing that we get less volatile estimates by so doing.

As we discussed above, the Jenkinson (1993) argument for consistency in applying the CAPM is persuasive, suggesting that to obtain a contemporaneous estimate of the forward risk premium it is preferable to combine an estimate of expected equity returns with an observed current risk free rate, either in nominal or in real terms. Nonetheless, it is still valid to ask how these forward estimates would have been formed historically, and so the last three columns in Table 1 present the average ex ante premia expected over the real Treasury Bill rate. These are presented for both the dividend growth $\left(R X D_{t}\right)$ and earnings growth $\left(R X Y_{t}\right)$ models, together with the realised returns $\left(R X_{t}\right)$. The long run arithmetic average risk premium over Bills from the dividend growth model is $4.61 \%$, and varies from a low of 3.5\% in the 1975-2009 sub-period to a high of $5.56 \%$ for the $1951-75$ sub-period. The first period of the $20^{\text {th }}$ century does not produce an estimate wildly different from the later period of the study (1951-2009), although it does show a decline in the expected risk premium, with an expected premium over bills of $5.13 \%$ compared to a later period premium of $4.37 \%$. The average estimate from the earnings growth model is $4.82 \%$. These figures stand in marked contrast to the arithmetic average risk premium of $6.95 \%$ over bills that we observe from realised returns, and can also be compared to the arithmetic premium over bills for the UK quoted in Dimson et al (Table 10, 2007) of 6.2\%. The important implication is that the long-run historical expected arithmetic risk premium over bills may have been $2.34 \%$ less than that the estimate obtained by an analysis of historical observed premia over the whole period, with an increased divergence of $2.75 \%$ being evident from 1975 on..

Of course, in any analysis of the historical risk premium, there is always an analysis of the return on equities compared to the realised return on government bonds, and indeed for long term planning (by corporates, investors and regulators) the cost of equity compared to long term interest rates is likely to be far more important than a 
cost compared to short term interest rates. ${ }^{15}$ Dimson et al (Table 11, 2007) show that for the UK the arithmetic average of this premium is $5.4 \%$, or $0.8 \%$ less than the premium earned over Treasury Bills. However, as argued above, there is a problem of consistency when examining ex ante returns. The correct procedure should be to use the same expectations in estimating long bond returns as in estimating long run equity returns, which implies using the contemporaneous inflation rate coupled with the contemporaneous gilt yield. The results of this analysis are shown in Table $2^{16}$, and the effect is to further decrease the historical expected risk premium. The arithmetic average of the expected real returns on gilts are shown in Table 2, Column 1 , and the arithmetic average risk premium figures over gilts are shown as $R X g D_{t}$ (the premium from the dividend growth model) and $R X g Y_{t}$ (the premium from the earnings growth model). These are contrasted with the realised equity returns compared to gilt yields $\left(R X g_{t}\right)$ in the final three columns of Table 2 . The first point of note is that the expected arithmetic average risk premia are over $1 \%$ less than that obtained using the Treasury Bill rate, at 3.54\% and 3.73\% from the dividend and earnings growth models respectively. Second, for the dividend growth model in particular, the expected risk premium shows little variation through the sub-periods. This is important, as when consistent approaches to expected inflation are taken in gilt and equity ex ante return estimation, the expected premium only varies between a low of $3.37 \%$ in the first sub period and 3.90\% in the second sub-period. The contrast with the Treasury Bill approach comes about because from the first column of Table 2, it can be seen that investors always expect a positive real return on gilts in every sub-period, and this expected return only varies between a low of $1.1 \%$ (second sub-period) and a high of $2.83 \%$ (third sub-period). By contrast, column 2 of Table 1 shows that in the second sub-period, investors actually experienced, on average, a negative real return on Treasury Bills. Previous studies of historically realised returns on gilts (e.g. Dimson et al, 2007) have shown a similar gap between the arithmetic average of real Treasury Bill and gilt returns, but also show a higher volatility of realised gilt returns. Dimson et al (2007, Tables 8 and 9) show that the geometric average, arithmetic average and standard deviation of Treasury Bill returns, 1900-2006 for the UK are 1\%, 1.2\% and $6.4 \%$ respectively, whereas the equivalent gilt returns data are $1.3 \%, 2.2 \%$ and $13.9 \%$.

\footnotetext{
${ }^{15}$ Theoretically, the risk-free comparator should be a bond with the same duration as the investment opportunity being appraised.

${ }^{16}$ To facilitate comparison of Gilt and equity returns, the equity data from table 1 are repeated in Table 2.
} 
The average expected real return on gilts from Table 2 is, at $2.25 \%$, close to the arithmetic average of the realised return from Dimson et al (2007), but the standard deviation of the expected returns is far lower at only $3.51 \%$. This suggests that most of the variation in realised real returns comes from unanticipated inflation shocks, as any variation in the expected real long gilt rate would show up in the standard deviation of expected returns.

We also examine the distributional properties of these estimates of expected returns, risk premia and growth. Actual returns suffer from being both significantly skewed and leptokurtic, and a joint test for normality show that this can be clearly rejected. By contrast, for expected returns $\left(\mathrm{RD}_{\mathrm{t}}\right.$ and $\left.\mathrm{RY} \mathrm{Y}_{\mathrm{t}}\right)$ we cannot reject the null hypothesis of a normal distribution in expected returns. Of course, if the growth in earnings or dividends, the fundamentals on which equities should priced, were non-normal, then there would be no reason to expect realised returns to exhibit normality. However, tests show that although there is weak evidence of skewness in earnings growth, normality cannot be rejected for either earnings growth or dividend growth. ${ }^{17} \mathrm{We}$ also test our fundamental-to-price ratios and growth observations for the presence of unit roots, and find that we can reject the hypothesis of a unit root in any of the estimates of $\mathrm{D}_{\mathrm{p}} / \mathrm{P}_{\mathrm{t}-1}, \mathrm{Y}_{\mathrm{p}} / \mathrm{P}_{\mathrm{t}-1}$, GD or GY, implying that all are mean-reverting.

Finally, as a cross-check we derive expected returns from the Ohlson and JuettnerNauroth (2005) FEG model. As explained above, in its two-period growth form the model places certain restrictions on the allowable level of short run and long run earnings growth. As this is clearly violated in individual years, the model can only be estimated for the entire sample period. Short run growth is estimated by taking the arithmetic average of the individual years' real earnings growth. The Shiller long run earnings estimate is then constructed as described above, with the first ten-year estimate being formed in 1937. The real earnings index and the implied price to long run real earnings ratios are illustrated in Figure 3. Successive annualised 10 year changes are then calculated and the arithmetic mean of these $(0.73 \%)$ is taken as the estimate of long run real earnings growth. Over the same period the short-run annual growth rate arithmetic mean is $1.55 \%$. Solving (3) above using these estimates yields

\footnotetext{
${ }^{17}$ Even in log form Rt is both skewed and leptokurtic.
} 
an estimated cost of equity capital of $6.25 \%$, a little above that obtained from the dividend and earnings growth model (5.8\%). Of course, this estimate is highly sensitive to the short run growth in earnings that is assumed. Assuming short run growth equal to long run growth reduces the implied cost of equity to $5.31 \%$.

\section{Forecasting dividend and earnings growth}

Whether or not longer run real dividend or earnings growth is predictable has important implications for estimating future expected returns. As is well known, if real dividend growth is essentially unpredictable and serially uncorrelated, then the best unbiased estimate of future dividend growth rate will be the past arithmetic average dividend growth. To appraise the predictability of dividend growth, the FF regressions of dividend growth on various predictor variables available at time $t$ are run. Specifically, real dividend growth (earnings growth) is regressed on the lagged dividend payout ratio, the lagged dividend/price ratio, lagged dividend (earnings) growth, and lagged market returns. Lagged price growth was included as an alternative to lagged market returns, but as the regressions were marginally less significant only the former are reported. Given the evidence that stock returns can be predicted by interest rate variables as well as the lagged dividend yield, variables capturing the lagged T-Bill rate, the term structure of interest rates and the gilt-equity ratio were included in regressions, but as none of these terms proved significant again only the basic regressions are reported ${ }^{18}$ in Table 3 . Dividend predictions are shown in the first four columns, whilst earnings predictions are shown in the last four columns.

Starting in 1955, quarterly estimates of GDP growth are available. Accordingly, taking care that estimates of economic growth would have been available to the market, we investigate whether any of the components of GDP are able to predict dividend or earnings growth. Post 1955, GDP, Consumption and Capital Formation (Investment) growth are included as independent variables, measured on a September to September basis to allow for delay in publication of the GDP figures. It turns out that investment growth has greater power to explain dividend and earnings growth

\footnotetext{
${ }^{18}$ Note that these regressions can only be estimated for 1928 on as the dividend payout ratio requires an earnings estimate to be available.
} 
than either GDP or consumption growth, and so only regressions using investment growth are reported.

Taking the whole period regressions first, at the one year horizon real dividend growth exhibits considerable predictability, and is forecast by the past market returns, the lagged dividend yield, the lagged growth in dividends, and the payout ratio. All of the coefficients exhibit the sign one would expect from theory. As in the early years of the FF study, the association of dividend growth with payout ratio is negative, as theory would predict given growth is likely to be lower when payout ratios are higher. The adjusted R-squared is similar to that of FF, at $35.2 \%$.

The real contrast with FF comes about when the post 1955 period is examined. For the period 1955-1999, FF find that only the past year's return is a significant explanatory variable, and their adjusted R-squared is a tiny $1 \%$. In the regression reported in the third and fourth columns, one year ahead dividend growth remains predictable, with an adjusted R-squared of $36 \%$. The payout remains significant but the one year growth in dividends becomes only marginally significant in the presence of lagged investment growth in the economy, which turns out to be a significant predictor of dividend growth. However, the lagged dividend yield loses its explanatory power. One point to note is that the adjusted R-squared figure is far higher than that reported in Vivian (2007), and that is probably explained by the inclusion of payout ratios and investment growth, neither of which feature in Vivian's regressions, and both of which are significant.

Columns 5-6 of Table 3 show that earnings growth is considerably less predictable than dividend growth. This contrasts with the FF finding, where earnings growth is the more predictable variable. Taking the whole period, only the lagged one and two year market return have significant explanatory power, and the adjusted R-squared is only $17.6 \%$. For the period 1955 on (reported in the final columns of Table 3), only the lagged Investment growth and the two-year lagged market returns have weak power (significant at the $10 \%$ level) to explain earnings growth. The adjusted Rsquared is $20.8 \%$. 
Unreported regressions for longer horizons suggest that any predictability in dividends and earnings growth for the whole period is limited to a role for the two year lagged return, with investment growth just failing to be significant.

\section{Combining dividend regressions with long run forecasts}

The conclusion from the analysis of the dividend and earnings growth regressions is that although one year growth has some predictability, which might argue the case for using a regression model to forecast short run growth, longer term growth, at least in dividends, is harder to predict. Crucially, we need to know whether the in-sample predictive power of dividend and earnings growth models described above extends to out of sample forecasting. In this respect, Vivian (2007) provides evidence that although in sample a-year and 5-year growth rates are predictable, out of sample the long run average provides the best estimate of expected dividend growth. However, we have shown that it is possible to build a better model of predicted dividend and earnings growth one period ahead. In general, if long run growth is unpredictable, then the best forecast of future dividend growth would be the long run arithmetic average growth rate. Whether it is better to use the long run average or to employ a forecasting model to estimate growth has clear implications for the estimation of the expected risk premium in the future.

Accordingly, we compare two simple models that can be used to estimate short-run growth in earnings or dividends. We first estimate a recursive regression model in the spirit of the type of model used in Pesaran and Timmermman (1995; 2000). Specifically, we assume that investors use the past 25 years of data ${ }^{19}$ to estimate parameters, but that they update their set of regressors to include lagged economic indicators once they have been available for the requisite period. The alternative model is simply to use the long run arithmetic average growth up until that point. The errors from these two approaches are summarised in Table 4, where we calculate mean errors, mean absolute errors, and mean squared errors. For earnings' forecasts, the results are unambiguous - the regression model dominates the use of long run averages whichever estimate of error is employed. For the dividend growth model, the regression model has an upward bias compared to long run averages, in that the

\footnotetext{
${ }^{19}$ Of course, one can argue for alternative long horizon estimates. Results using ten year rolling forecasts are qualitatively similar.
} 
mean error is $0.73 \%$ compared to the error from the use of long run averages of $0.14 \%$. Nonetheless, the regression model exhibits lower absolute errors and lower mean squared errors. The implication is that in terms of estimating the expected return on equity or expected risk premium, we can do better by employing a direct estimate of likely short run growth. This suggests alternative model for the investigation of historically expected returns on equity, so we estimate short run expected growth using a recursive model, with long run growth being estimated on the equivalent period's rolling average growth.

Doing so yields some interesting results, which are shown in Table 5. Whilst the estimates from this exercise are slightly higher than those shown in Tables 1 and 2, at $5.87 \%$ and $5.99 \%$ from the dividend and earnings growth models respectively, they exhibit very low volatility, as might be expected from the use of long run average growth rates. Arguably, this much "tighter" estimate of rationally expected future returns helps in addressing Cochrane's (2001) "surprisingly underappreciated problem". The individual year estimates from this process are summarised in Figure 4.

So in very round numbers, it seems that investors may have been pricing equities as though they thought an expected real return of around 5.8\% to 6\% was reasonable. Historically, all our estimates seem to converge on this range of numbers. Of course, in the end they were pleasantly surprised, if one takes an average of annually realised returns as one's guide, as that figure reveals a return of $8.14 \%$ over our sample period. Perhaps more interesting is that over the long haul, their arithmetic average expectations would have roughly been in line with the realised geometric average return over this same period, which was $6.01 \%$ (Table 1 ).

\section{Implications for the expected return and the equity risk premium}

The critical choices when forecasting the expected return are: the expected short-run and long-run dividend growth; the adjustment needed (if any) to arrive at a simple annual rate for discounting purposes, and; whether to make a conditional forecast (i.e. one based on the current dividend yield) or an unconditional one (based on the assumption of mean reversion to the long run dividend yield). The latter 
unconditional estimate will usually imply a short run change in market prices so that the dividend yield reverts to its long run mean value.

We start with summarising the unconditional estimates from our various models in Table 6. We show (for all models except the FEG model) the results from using the full period for which historical returns are available, and the period from 1975 onwards. If the Table 1 and 2 estimates are viewed as unconditional, and market prices are formed on the basis of rational expectations (in particular this implies that prices are not excessively volatile), then as Fama and French (2002) show, the estimation of an expected annual simple return (assuming this is equivalent to the arithmetic average return) requires that the estimates formed from the mean dividend or earnings growth model expected returns are uplifted by half the difference between the variance of the price growth series and the variance of the dividend growth (or earnings growth) model returns. If one believes that it is the risk premium that is stationary, then as these are historical estimates, the appropriate risk free rate would be the historical real yield on gilts. The resulting calculations (for expected returns on the market and the expected risk premium) are shown in the "bias adjusted" columns of Table 6. The implied expected "bias adjusted" return on the dividend growth model is then $7.50 \%$, and the historical arithmetic risk premium is $5.25 \%$. Because the increased volatility of the earnings growth series results in a much smaller "bias adjustment", the implied expected arithmetic return on the earnings growth model is $7.03 \%$ and the expected risk premium over gilts is $4.76 \%$. From 1975 onwards, although expected returns have been higher, the lower volatility in price growth (see Table 1) implies a considerably smaller bias adjustment leading to lower expected returns $(7.17 \%$ and $6.88 \%$ from dividend and earnings growth models respectively) and lower risk premia ( $4.92 \%$ and $4.63 \%$ respectively). If one accepts the arguments of Wright et al (2003) that the expected return on equities may be more stable than the expected risk premium, and the data in Table 2 lend some support to this, then it would be preferable to estimate the expected return on equities, rather than the equity risk premium, directly. Furthermore, following the Jenkinson (1993) argument, this is important if the intention is to use the current yield on Gilts (as appears to be regulatory practice) in calculations of the cost of equity capital. 
However, these calculations in the "bias adjusted" columns of Table 6 make the strong assumption that there is no excess volatility in market prices. As we discuss below, it seems hard to argue that prices should ultimately be more volatile than the fundamentals that drive valuation. Such a view leads to the conclusion that a bias adjustment is inappropriate in the determination of rational discount rates and estimates of the cost of equity capital. The calculations in the "no bias adjustment" columns of Table 6 show the expected return and premium without such bias adjustment. Implied returns for the simple DGM and YGM models are, of course, then identical to the historical estimates in Table 2, but we also show the effect of estimating the risk premium using both the FEG/Shiller model (estimated with two alternative short run growth assumptions) and the recursive regression model. The implied risk premia range from $2.46 \%$ (from the recursive DGM model, 1975 on) to $4.0 \%$ from the FEG/Shiller model estimated with a higher short run growth rate.

The important point in the above analysis is that unless one believes market prices are, on average, rational, then adjusting these historical observations for half the difference in variance between actual price growth and fundamental growth merely serves to give estimated costs of equity, or estimated risk premia, an upward bias. Yet the evidence in favour of excess volatility seems compelling (for a review, see Shiller 2003). Of course, both future dividends and future discount rates can change, so that simply focussing on expected fundamentals and growth in fundamentals ignores expected discount rate changes. If one combines high enough growth assumptions with a low enough assumed ex-ante premium, as $R_{m}$ and $g_{t}$ in (1) converge, one can justify historically observed volatility levels. This is the basic approach taken in Armitage et al (2009). However, there are several problems with this approach. First, as we note above, as we can reject the hypothesis of a unit root in any of the estimates of $\mathrm{D}_{\mathrm{p}} / \mathrm{P}_{\mathrm{t}-1}, \mathrm{Y}_{\mathrm{p}} / \mathrm{P}_{\mathrm{t}-1}, \mathrm{GD}$ or $\mathrm{GY}$, the implication is that all are mean-reverting. If there were permanent shifts in expected returns, then either growth or the dividend (or earnings) to price ratio should exhibit signs of stationarity, and they do not. As Campbell and Shiller (1997) observe, if the level of $\mathrm{D}_{\mathrm{p}} / \mathrm{P}_{\mathrm{t}-1}$ does not permanently change, then its level must be forecasting something - either it signals changes in the expected growth in the fundamentals so that $\mathrm{D}_{\mathrm{p}} / \mathrm{P}_{\mathrm{t}-1}$ mean reverts, or it must be forecasting mean reversion through price changes. They provide evidence for the latter and that is consistent with what we observe here. Further evidence in favour of 
the excess volatility hypothesis can be found in studies of the cross-section of stock returns, where research evidence, backed by recent theoretical models, shows both short term under-reaction and long term over reaction (Subrahmanyam, 2007). Finally, recall that the basic Fama-French (2002) projections replicated in Tables 1 and 2 make the unreasonable assumption that investors project the future from the past year, so that the estimates from such a naïve model will almost certainly overestimate expected changes in fundamentals. On balance, it seems difficult to justify the assumption of an uplift to historically expected return estimates, particularly if they imply substantial corrections to market prices. So at this point, we move on to consider what may be implied by these prices at the end of our study.

\section{Ex ante estimates at the end of our sample period}

The long run average dividend to opening price ratio in December 2009 was $4.7 \%$ compared to the long run average real dividend/opening price ratio (see Table 1) of $4.58 \%$. However, that ratio owes a great deal to depressed opening prices. Prices rose by just over $22 \%$ in 2009, and the end December 2009 dividend yield on the FTASI had fallen to $3.2 \%$. Converting this to a forecast real $\mathrm{D}_{2010} / \mathrm{P}_{2009}$ requires a forecast of short run real dividend growth. Applying the dividend growth model in Table 3 gives a forecast growth for 2010 of $-6.66 \%$.. The earnings growth version of the model suggests a steeper decline of $12.3 \%$. The implied expected return is then given as follows. First, in the case of the dividend growth model, the expected dividend to opening price ratio will be $3.2 \% \times(1-0.066)=2.99 \%$. Expected long run growth (from our 25 rolling average end in 2009) is 1.06\%, implying an expected long run return (from [2]) above of $4.05 \%$ real. The earnings growth model is estimated in a similar fashion. These calculations are given in the first column, rows 1 and 2, of Table 7. Alternatively, one can simply ignore the regression model altogether and simply take the latest 25 year average long run arithmetic average growth rate in dividends (earnings) as the indicator of both short run and long run growth. ${ }^{20}$ This would forecast the dividend to opening price ratio of $3.2 \% \mathrm{x}(1+0.0121)=3.24 \%$. Adding the long run growth of $1.06 \%$ suggests an expected real return to equities of $4.30 \%$. A similar calculation for the earnings model gives an estimate of $4.46 \%$. These calculations form the basis of the last two rows in Table 7. Any bias

\footnotetext{
${ }^{20}$ This would be the preferable approach if the regression models lacked power to explain out of sample returns, as in Vivian (2007).
} 
adjustment now needs to reflect the much lower variance of the recursive regression estimates from the bottom panel of Table 5, together with the variance of prices in the twenty five year period ending in December 2009. Half the difference in the variances then gives the potential bias adjustment, which is shown in the third column of Table 7. The bias-adjusted costs of equity range from $5.32 \%$ to a maximum of $5.76 \%$. Last, as these are current ex ante returns the appropriate risk free rate is the December 2009 medium term index-linked gilt yield which was 1.14\%. The resultant risk premia range from $4.18 \%$ to $4.62 \%$ on a bias-adjusted basis, and from $2.89 \%$ to $3.32 \%$ on a non-bias adjusted basis.

The clear implication of these numbers is that future returns on equities are likely to be well below historically expected returns. Alternatively, an interpretation of this forecast is that a reversion to the long run mean real dividend/opening price ratio of $4.58 \%$ by the end of 2010 would imply a serious correction to December 2009 prices.

Of course, one can argue for higher long run expected growth estimates, possibly as high as the rate of GDP growth or at least GDP per capita growth. The Dimson et al (2005) long run (1900-2004) estimate of GDP per capita growth is $1.83 \%$ for the UK. However, the Dimson et al (Ch. 3, 2005) results (which update those of Bernstein and Arnott, 2003) show that dividend growth is less than GDP growth, and indeed less than GDP per capita growth, in most countries. The rationale for this, put forward in Bernstein and Arnott (2003), is that a substantial part of economic growth comes from entrepreneurial activity and new firms not included in the main market indices. Set in that context, the growth estimates from the recursive model look to be towards the higher end of reasonable expectations.

\section{Discussion and conclusions}

The above estimates raise several issues. Leaving aside the question of the risk premium, and concentrating on the expected cost of equity, we first have the question of whether to use the historical ex ante estimates presented in Table 6, or the current ex ante estimates from Table 7. The former are appropriate bases if we believe meanreversion will hold, but the uncomfortable corollary is that these estimates imply that the market is over-valued as of December 2009. The alternative is to assume that some permanent shift in expectations has taken place, and that markets are correctly 
valued, in which case the Table 7 estimates would be preferred. A second and arguably related question is what should be done about the possible bias adjustment? If we start with a contemporary (December 2009) estimate, then it seems reasonable to recognise that price volatility could be important, given the central estimate is of permanently lower expected returns than the long run historical averages. As such, incorporating a bias adjustment seems reasonable. However, if we start with the assumption of mean-reversion, then large price falls are already implied by the forecast, so that embedding a potential bias adjustment could be viewed as doublecounting. Furthermore, an expected price-correction implicitly recognises that prices are excessively volatile, so that incorporating a bias-adjustment that essentially reflects investor irrationality seems highly questionable.

Last, a real question for regulatory purposes is whether a simple expected rate of return is actually appropriate. Returning to the fact that Fama (1996) highlights the implied right skew in cash flow estimates is a corollary of discounting at expected simple rates of return, it is by no means obvious that such cash flow forecasts are compatible with regulatory budgeted cash flows, which one could argue are more likely to be based upon median cash flows or an assumption of normally distributed cash flows. In addition, there are the estimation bias issues highlighted by Blume (1973) and Indro and Lee (1997) which point to the use of a weighted average of arithmetic and geometric mean returns in estimating required rates of return. In short, it is far from obvious that the potential bias adjusted simple rates of return derived above can be unambiguously recommended as providing the optimal estimate of equity cost of capital for regulatory purposes even if there is no "excess volatility" in market prices.

The focus of the paper has been on arithmetic averages, or estimates of the simple annual rate of return, which feature heavily in applications such as discount rate estimation and regulatory cost of capital. We have shown that historical estimates of the mean of the long run expected return on equities are between $5.29 \%$ and $6.76 \%$ resulting in an arithmetic risk premium over gilts of between $2.46 \%$ and $3.93 \%$. This estimate of the risk premium over gilts treats expected inflation in equity and gilt returns consistently, something which past studies miss by focussing on realised 
returns on gilts. These risk premia are lower than the figures typically quoted in UK utility regulation price-setting exercises.

Estimates of the expected arithmetic average return on equities going forward depend upon the growth rates assumed for future dividends and on the procedure used to estimate return volatility. The recent extreme movement in markets cause problems for any estimation of the expected return based on current yields and prices, but reasonable estimates that incorporate a "Fama-French bias adjustment" suggest the maximum expected cost of equity is between $5.32 \%$ and $5.76 \%$. This translates into a risk premium of $4.18 \%$ to $4.62 \%$ purely because of the currently low level of risk-free rates. Of course, if one believes that current market prices are rational, a case can be made for dropping any such bias adjustment and then the risk premium is in the range $2.89 \%$ to $3.32 \%$.

Two central recommendations for regulatory practice are: consistency in estimating the risk premium, in that estimating an expected cost of equity directly, and then deducting the chosen risk-free rate is the preferred approach, and; consistency in the approach to estimating ex ante returns is preferred. We can either assume reversion to the mean in fundamentals to price ratios, which implies there is no need for any uplift to expected returns. Alternatively, we can assume no mean reversion, in which case some allowance for potential price volatility seems reasonable. Indeed, given uncertainty about possible outcomes, some sort of weighted average might be a possibility. Such an approach might suggest the reasonable range of expected cost of equity is between $5.5 \%$ and $6 \%$. 


\section{References}

Armitage, S., Fitzgerald, A., and Adams, A (2009), 'Excess Volatility Re-visited', University of Edinburgh Business School Working Paper 09.04

Barclays Capital (2007), Equity Gilt Study 2007 Barclays Capital, London.

Bernstein, W. and R. Arnott (2003), 'Earnings Growth: The Two Percent Dilution", Financial Analysts' Journal, 59(5), 47-55.

Blume, M.E. (1974), 'Unbiased Estimators of Long-Run Expected Rates of Return', Journal of the American Statistical Association, 69 (347), Sept, 634-638.

Campbell, J.Y. (1999), 'Asset Prices, Consumption and the Business Cycle', in J. Taylor and M.Woodford (eds.), Handbook of Macroeconomics, Vol 1 1231-1303.

Claus, J. and Thomas, J. (2001),'Equity Premia as Low as Three Percent? Evidence from Analysts' Forecasts for Domestic and International Stock Markets' Journal of Finance 56(5), 1629-1666.

Cochrane, J.H. (2001) Asset Pricing. Princeton and Oxford. Princeton University Press.

Competition Commission (2010). Bristol Water plc Price Limits Determination Final determination $\left(14^{\text {th }}\right.$ Sept 2010).

Cooper, I. (1996) 'Arithmetic versus Geometric Mean Estimators: Setting Discount Rtaes for Capital Budgeting’, European Financial Management, 2(2), 157-167.

Dimson, E., Marsh, P. and Staunton, K. (2002), Triumph of the Optimists: 101 Years of Global Investment Returns, Princeton New Jersey: Princeton University Press

Dimson, E., Marsh, P. and Staunton, K. (2005), Global Investment Returns Yearbook, 2005, London: ABN AMRO/ LBS.

Dimson, E. P. Marsh, and M. Staunton (2006) 'The Worldwide Equity Premium: A Smaller Puzzle', http://ssrn.com/abstract $=891620$

Dimson, E., Marsh, P. and Staunton, K. (2007), Global Investment Returns Yearbook, 2007, London: ABN AMRO/ LBS.

Fama, E.F. (1996), 'Discounting Under Uncertainty', Journal of Business, 69(4), October, pp 415-428.

Fama, E.F. and French, K.R. (2002), 'The Equity Premium', Journal of Finance, 57, April, pp 637-660.

Gode, D., and Mohanran, P. (2003), 'Inferring the Cost of Capital Using the Ohlson Juettner Model, Review of Accounting Studies, 8, 399-431. 
Indro, D.C. and Lee, W.Y. (1997), 'Biases in Arithmetic and Geometric Averages as Estimates of Long-Run Expected Returns and Risk Premia', Financial Management, (26:4), Winter, pp 81-90.

Jenkinson, T. (1993), 'The cost of equity finance: conventional wisdom reconsidered', Stock Exchange Quarterly with Quality of Markets Review, Autumn pp. 23-27.

Lundholm, R. and O'Keefe, T. (2001), 'Reconciling Value Estimates from the Discounted Cash Flow Model and the Residual Income Model', Contemporary Accounting Research, (18:2), Summer, 311-335.

Mehra, R. and Prescott, E.C. (1985), 'The equity premium: a puzzle', Journal of Monetary Economics, vol. 15, pp. 145-161.

Ohlson, J.A. and Juettner-Nauroth, B.E. (2004), 'Expected EPS and EPS Growth as Determinants of Value', Review of Accounting Studies, 10, 349-365

Shiller, R.J. (1981), 'Do stock prices move too much to be justified by subsequent changes in dividends?', American Economic Review, June, pp. 412-436.

Subrahmanyam, A. (2007), 'Behavioural Finance: A Review and Synthesis', European Financial Management 14(1), 12-29.

Vivian, A. (2007), 'The UK Equity Premium: 1901-2004', Journal of Business Finance and Accounting, Vol. 34, 9\&10, pp. 1496-1527.

Wright, S., Mason, R. and Miles, D. (2003), A Study into Certain Aspects of the Cost of Capital for Regulated Utilities in the UK, Smithers \& Co. Ltd, London.

Wright, S., Mason, R. Satchell, S., Hori, K. and Baskaya, M. (2006), Report on the Cost of Capital provided to Ofgem, Smithers \& Co. Ltd, London. 


\section{Appendix 1: Equity Market data descriptors from Global Financial Data}

From http://www.globalfinancialdata.com/index.php3?action=detailedinfo \&id=2546

Stock market data:

Country: United Kingdom

Begins: December 1923 and January 1939

Sources: Journal of the Institute of Actuaries, (LXII), part 2, no. 304, pp. 321-331, New York Stock Exchange Bulletin (1929-1938), Central Statistical Office Annual Abstract of Statistics, London: CSO (1939-1988), Eurostat (1989-) for the Financial Times-Actuaries yields and The Economist (1939-1965), Central Statistical Office, Monthly Digest of Statistics, London: CSO (1966-) for the FTI30 yields; London and Cambridge Economic Service, Key Statistics of the British Economy, London: L\&CES, 1966 for earnings yield from 1927 through 1962.

Notes: Dividend yields were calculated by the Actuaries beginning in 1923. Monthly yields for the Financial Times 30 industrials are also provided. All yield data are monthly. The Financial Times calculated earnings yield data $(\mathrm{E} / \mathrm{P})$ rather than price/earnings ratios, so earnings yield data have been inverted to give the price earnings ratio. Price/earnings ratios are provided for the FTI-30 index beginning in 1955 with data annual through 1966 and monthly thereafter. The price/earnings ratio is also provided for the Financial Times-Actuaries Index with annual data from 1927 through 1962 and monthly data beginning in April 1962. This series is based upon data calculated for the Actuaries General index through 1962, the FT Non-Financials from April 1962 through January 1993, and the FT All-Share from February 1993, which begins daily data on June 14, 1993 on. 
Table 1 Inflation, real Treasury Bill, dividend and earnings growth, market returns and expected real returns, 1925-2009.

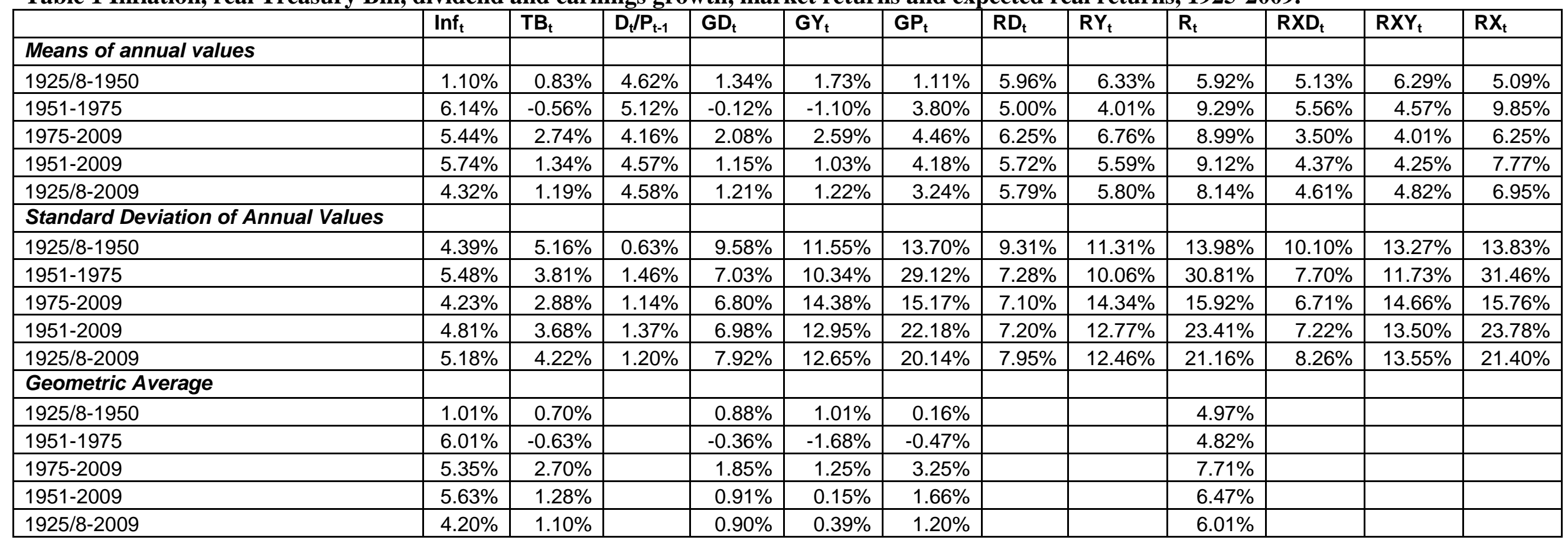

The columns show respectively the arithmetic averages, standard deviations and geometric averages for inflation (Inft), real Treasury Bill returns $(T B t)$ real dividends over opening prices $\left(D_{t} / P_{t-1}\right)$, real growth in dividends $\left(G D_{t}\right)$, real growth in earnings $\left(G Y_{t}\right)$, real growth in equity market prices $\left(G P_{t}\right)$, the estimated forward return from the dividend growth model $\left(R D_{t}=D_{t} / P_{t-1}+G D_{t}\right)$, the estimated forward return from the earnings growth model $\left(R Y_{t}=D_{t} / P_{t-1}+G Y_{t}\right)$, the realised real return on the market index $\left(R_{t}\right)$, and the estimated risk premia over Treasury Bills resulting from the dividend growth $\left(R X D_{t}=R D_{t}-T B_{t}\right)$, earnings growth $\left(R Y D t=R Y_{t}-T B_{t}\right)$ and market return $\left(R X_{t}\right)$ models, respectively. 
Table 2 Real Gilt yields, dividend and earnings growth, market returns and expected real returns, 1925-2009.

\begin{tabular}{|l|r|r|r|r|r|r|r|}
\hline & $\mathbf{G I L T}_{\mathbf{t}}$ & $\mathbf{R D}_{\mathbf{t}}$ & $\mathbf{R Y}_{\mathbf{t}}$ & $\mathbf{R}_{\mathbf{t}}$ & $\mathbf{R X}_{\mathbf{g}} \mathbf{D}_{\mathbf{t}}$ & $\mathbf{R X}_{\mathbf{g}} \mathbf{Y}_{\mathbf{t}}$ & $\mathbf{R X}_{\mathbf{g t}}$ \\
\hline Means of annual values & & & & & & & \\
\hline $1925 / 8-1950$ & $2.59 \%$ & $5.96 \%$ & $6.33 \%$ & $5.92 \%$ & $3.37 \%$ & $4.31 \%$ & $3.32 \%$ \\
\hline $1951-1975$ & $1.10 \%$ & $5.00 \%$ & $4.01 \%$ & $9.29 \%$ & $3.90 \%$ & $2.92 \%$ & $8.19 \%$ \\
\hline $1975-2009$ & $2.83 \%$ & $6.25 \%$ & $6.76 \%$ & $8.99 \%$ & $3.42 \%$ & $3.93 \%$ & $6.16 \%$ \\
\hline $1951-2009$ & $2.10 \%$ & $5.72 \%$ & $5.59 \%$ & $9.12 \%$ & $3.62 \%$ & $3.50 \%$ & $7.02 \%$ \\
\hline $1925 / 8-2009$ & $2.25 \%$ & $5.79 \%$ & $5.80 \%$ & $8.14 \%$ & $3.54 \%$ & $3.73 \%$ & $5.89 \%$ \\
\hline $\begin{array}{l}\text { Standard Deviation of Annual } \\
\text { Values }\end{array}$ & & & & & & \\
\hline $1925 / 8-1950$ & $4.66 \%$ & $9.31 \%$ & $11.31 \%$ & $13.98 \%$ & $9.91 \%$ & $13.02 \%$ & $13.76 \%$ \\
\hline $1951-1975$ & $3.05 \%$ & $7.28 \%$ & $10.06 \%$ & $30.81 \%$ & $7.82 \%$ & $11.33 \%$ & $31.54 \%$ \\
\hline $1975-2009$ & $2.24 \%$ & $7.10 \%$ & $14.34 \%$ & $15.92 \%$ & $7.12 \%$ & $14.80 \%$ & $15.64 \%$ \\
\hline $1951-2009$ & $2.75 \%$ & $7.20 \%$ & $12.77 \%$ & $23.41 \%$ & $7.43 \%$ & $13.45 \%$ & $23.74 \%$ \\
\hline $1925 / 8-2009$ & $3.47 \%$ & $7.95 \%$ & $12.46 \%$ & $21.16 \%$ & $8.31 \%$ & $13.42 \%$ & $21.39 \%$ \\
\hline
\end{tabular}

The columns show respectively the arithmetic averages, standard deviations and geometric averages for real expected Gilt yields $($ GILTt), the estimated forward return from the dividend growth model $\left(R D_{t}=D_{t} / P_{t-1}+G D_{t}\right)$, the estimated forward return from the earnings growth model $\left(R Y_{t}=D_{t} / P_{t-1}+G Y_{t}\right)$, the realised real return on the market index $\left(R_{t}\right)$, and the estimated risk premia over Gilt yields resulting from the dividend growth $\left(R X_{g} D_{t}=R D_{t}-G I L T_{t}\right)$, earnings growth $\left(R Y_{g} D t=R Y_{t}-G I L T_{t}\right)$ and market return $\left(R_{g} X_{t}\right)$ models, respectively. 
Table 3 Real Dividend and Earnings growth regressions. The columns show the results of regressing the real growth in dividends $\left(G D_{t}\right)$ or the real growth in earnings $\left(G Y_{t}\right)$, on the following variables: lagged real realised return on the market index $\left(R_{t-1}\right),\left(R_{t-2}\right)$; ), lagged real dividend or real earnings yield ratios $\left(D_{t-1} / P_{t-2}\right),\left(E_{t-1} / P_{t-2}\right)$; lagged real dividend growth $\left(G D_{t-1}\right)$ or real growth in earnings $\left(G Y_{t-1}\right)$; lagged dividend payout ratios (t-1); and lagged Gross Domestic Capital Formation (Investment) growth $\left(I_{t-1}\right)$.

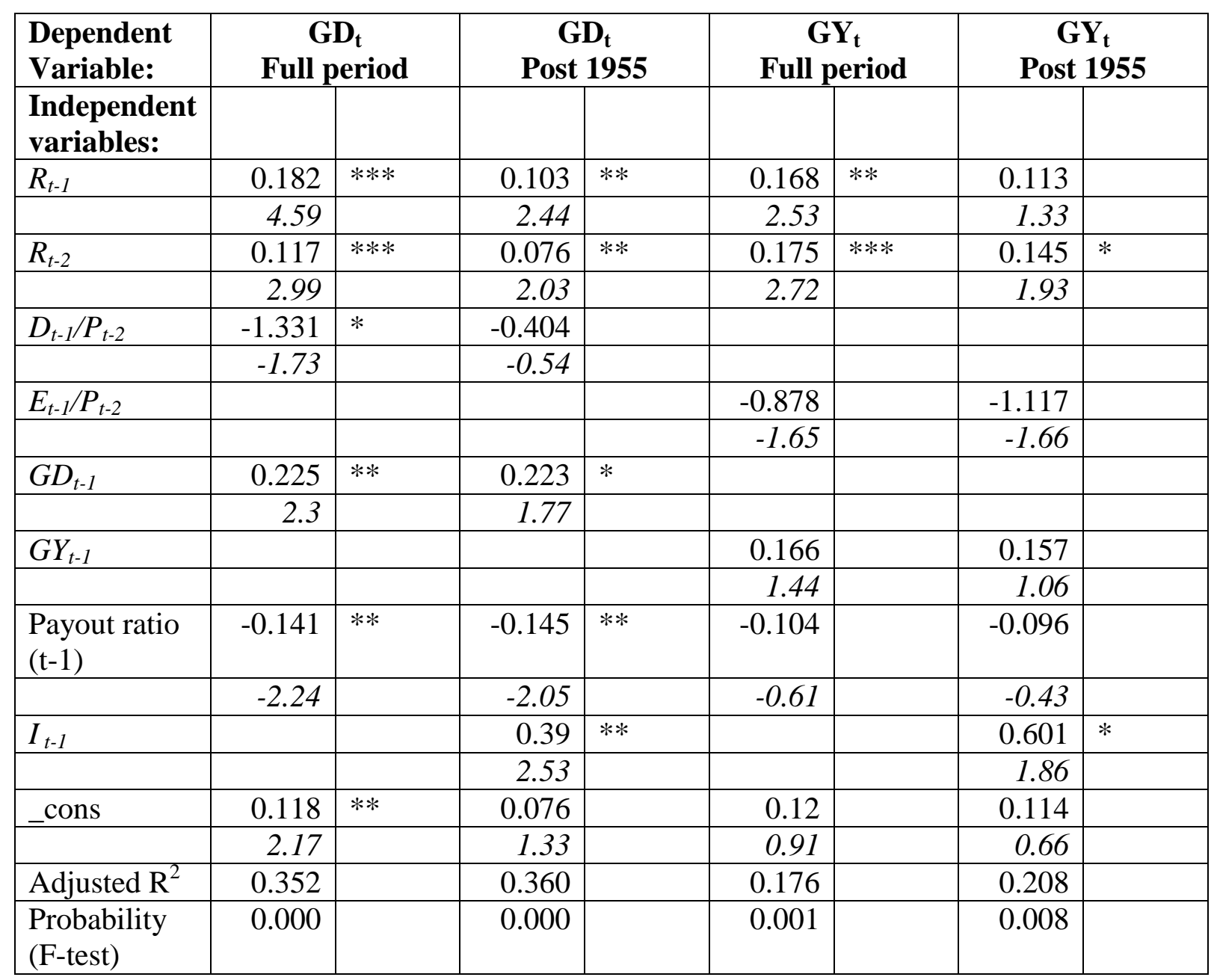


Table 4: Out of Sample Forecasting Errors. The table shows Mean Error, Mean Absolute Error, and Mean Squared Error for one period ahead forecasts from two alternative forecasting models. These models are from rolling 25 year regression models estimated using the regressions described in Table 3, and a simple long-run mean to date growth estimate for both dividend and earnings growth.

\begin{tabular}{|l|r|l|l|l|}
\hline & \multicolumn{2}{|l|}{$\begin{array}{l}\text { Dividend Growth } \\
\text { Model }\end{array}$} & \multicolumn{2}{l|}{$\begin{array}{l}\text { Earnings Growth } \\
\text { Model }\end{array}$} \\
\hline $\begin{array}{l}\text { Error } \\
\text { measure: }\end{array}$ & $\begin{array}{l}\text { GD } \\
\text { Regression }\end{array}$ & $\begin{array}{l}\text { Long } \\
\text { run } \\
\text { average } \\
\text { GD }\end{array}$ & $\begin{array}{l}\text { GY } \\
\text { Regression }\end{array}$ & $\begin{array}{l}\text { Long } \\
\text { run } \\
\text { average } \\
\text { GY }\end{array}$ \\
\hline Mean error & $0.73 \%$ & $0.14 \%$ & $-0.06 \%$ & $0.20 \%$ \\
\hline $\begin{array}{l}\text { Mean absolute } \\
\text { error }\end{array}$ & $3.93 \%$ & $5.66 \%$ & $7.26 \%$ & $10.34 \%$ \\
\hline $\begin{array}{l}\text { Mean squared } \\
\text { error }\end{array}$ & $0.25 \%$ & $0.50 \%$ & $0.91 \%$ & $1.73 \%$ \\
\hline
\end{tabular}

Table 5: Expected return on equity estimates from the recursive regression model.

The estimates are made by employing the rolling 25 year regression models estimated using the regressions described in Table 3 to estimate the forecast dividend one period ahead, and then using the 25-year rolling mean to forecast either long-run dividend or earnings growth

\begin{tabular}{|l|r|r|}
\hline Full period & GD model & GY model \\
\hline Mean estimated expected return & $5.87 \%$ & $5.99 \%$ \\
\hline Standard deviation of expected return & $1.44 \%$ & $1.92 \%$ \\
\hline $\mathbf{1 9 5 1 - 1 9 7 5}$ & & \\
\hline Mean estimated expected return & $6.72 \%$ & $6.99 \%$ \\
\hline Standard deviation of expected return & $1.63 \%$ & $1.99 \%$ \\
\hline 1975-2009 & & \\
\hline Mean estimated expected return & $5.29 \%$ & $5.44 \%$ \\
\hline Standard deviation of expected return & $0.89 \%$ & $1.52 \%$ \\
\hline
\end{tabular}


Table 6: Historical mean Ex ante simple annual return estimates.

\begin{tabular}{|c|c|c|c|c|c|c|c|}
\hline Basis of estimation & $\begin{array}{l}\text { Potential } \\
\text { "bias } \\
\text { adjustment" } \\
\text { basis }\end{array}$ & $\begin{array}{l}\mathrm{E}(\mathrm{Rm}) \\
\text { with no } \\
\text { bias } \\
\text { adjustment }\end{array}$ & $\begin{array}{l}\text { Potential } \\
\text { bias } \\
\text { adjustment }\end{array}$ & $\begin{array}{l}\mathrm{E}(\mathrm{Rm}) \text { with } \\
\text { bias } \\
\text { adjustment }\end{array}$ & $\begin{array}{l}\text { Gilt } \\
\text { yield }\end{array}$ & $\begin{array}{l}\text { ERP with } \\
\text { bias } \\
\text { adjustment }\end{array}$ & $\begin{array}{l}\text { ERP with } \\
\text { no bias } \\
\text { adjustment }\end{array}$ \\
\hline LR historical DGM post 1925 & $1 / 2$ diff & $5.79 \%$ & $1.71 \%$ & $7.50 \%$ & $2.25 \%$ & $5.25 \%$ & $3.54 \%$ \\
\hline LR historical YGM post 1928 & $1 / 2$ diff & $5.80 \%$ & $1.23 \%$ & $7.03 \%$ & $2.25 \%$ & $4.78 \%$ & $3.55 \%$ \\
\hline LR historical DGM post 1975 & $1 / 2 \operatorname{diff}$ & $6.25 \%$ & $0.92 \%$ & $7.17 \%$ & $2.83 \%$ & $4.34 \%$ & $3.42 \%$ \\
\hline LR historical YGM post 1975 & $1 / 2$ diff & $6.76 \%$ & $0.12 \%$ & $6.88 \%$ & $2.83 \%$ & $4.05 \%$ & $3.93 \%$ \\
\hline FEG/Shiller SRG > LRG & none & $6.25 \%$ & n.a. & n.a. & $2.25 \%$ & n.a. & $4.00 \%$ \\
\hline FEG/Shiller SRG = LRG & none & $5.31 \%$ & n.a. & n.a. & $2.25 \%$ & n.a. & $3.06 \%$ \\
\hline $\begin{array}{l}\text { Recursive regression estimates, DGM full } \\
\text { period }\end{array}$ & none & $5.87 \%$ & n.a. & n.a. & $2.25 \%$ & n.a. & $3.62 \%$ \\
\hline $\begin{array}{l}\text { Recursive regression estimates, YGM full } \\
\text { period }\end{array}$ & none & $5.99 \%$ & n.a. & n.a. & $2.25 \%$ & n.a. & $3.74 \%$ \\
\hline $\begin{array}{l}\text { Recursive regression estimates, DGM } 1975 \\
\text { on }\end{array}$ & none & $5.29 \%$ & n.a. & n.a. & $2.83 \%$ & n.a. & $2.46 \%$ \\
\hline $\begin{array}{l}\text { Recursive regression estimates, YGM } 1975 \\
\text { on }\end{array}$ & none & $5.44 \%$ & n.a. & n.a. & $2.83 \%$ & n.a. & $2.61 \%$ \\
\hline
\end{tabular}

Columns show: the basis of the estimate (LR = long run, DGM = dividend growth, YGM = earnings growth); the type of "bias" adjustment employed (if any), where " $1 / 2$ diff" refers to an uplift of half the difference between the historical price growth variance and the historical dividend or earnings growth variance; the base estimate $\left(\mathrm{D}_{1} / \mathrm{P}_{0}+\right.$ Growth, variously estimated); the amount of the bias adjustment; the resulting ex ante annual simple return estimate; the consistent estimate of gilt return (the historical real gilt yield); and the resultant estimate of the equity risk premium over the gilt rate with and without "bias" adjustment. 
Table 7: Ex ante returns as at December 2009.

\begin{tabular}{|c|c|c|c|c|c|c|c|}
\hline Basis of estimation & $\begin{array}{l}\text { Potential } \\
\text { "bias } \\
\text { adjustment" } \\
\text { basis }\end{array}$ & $\begin{array}{l}\mathrm{E}(\mathrm{Rm}) \\
\text { with no } \\
\text { bias } \\
\text { adjustment }\end{array}$ & $\begin{array}{l}\text { Potential } \\
\text { bias } \\
\text { adjustment }\end{array}$ & $\begin{array}{l}\mathrm{E}(\mathrm{Rm}) \text { with } \\
\text { bias } \\
\text { adjustment }\end{array}$ & $\begin{array}{l}\text { Gilt } \\
\text { yield }\end{array}$ & $\begin{array}{l}\text { ERP with } \\
\text { bias } \\
\text { adjustment }\end{array}$ & $\begin{array}{l}\text { ERP with } \\
\text { no bias } \\
\text { adjustment }\end{array}$ \\
\hline Dec 09 DY, SRGD \& LRGD & $1 / 2$ diff & $4.05 \%$ & $1.30 \%$ & $5.35 \%$ & $1.14 \%$ & $4.21 \%$ & $2.91 \%$ \\
\hline Dec 09 DY, SRGY \& LRGY & $1 / 2 \operatorname{diff}$ & $4.03 \%$ & $1.29 \%$ & $5.32 \%$ & $1.14 \%$ & $4.18 \%$ & $2.89 \%$ \\
\hline Dec 09 DY, LRGD & $1 / 2 \operatorname{diff}$ & $4.30 \%$ & $1.30 \%$ & $5.60 \%$ & $1.14 \%$ & $4.46 \%$ & $3.16 \%$ \\
\hline Dec 09 DY, LRGY & $1 / 2 \operatorname{diff}$ & $4.46 \%$ & $1.29 \%$ & $5.76 \%$ & $1.14 \%$ & $4.62 \%$ & $3.32 \%$ \\
\hline
\end{tabular}

Columns show: the basis of the estimate (SR = short run, LR = long run, GD = dividend growth, GY = earnings growth); the type of "bias" adjustment employed (if any), where " $1 / 2$ diff" refers to an uplift of half the difference between the historical price growth variance and the historical dividend or earnings growth variance; the base estimate $\left(D_{2010} / P_{2009}+\right.$ Growth, variously estimated); the amount of the potential bias adjustment; the resulting ex ante annual simple return estimate; the consistent estimate of gilt return (the ex ante real gilt yield); and the resultant estimate of the equity risk premium over the gilt rate with and without "bias" adjustment. 
Figure 1: Real dividend and earnings yields for the UK

Earnings and Dividend Yields

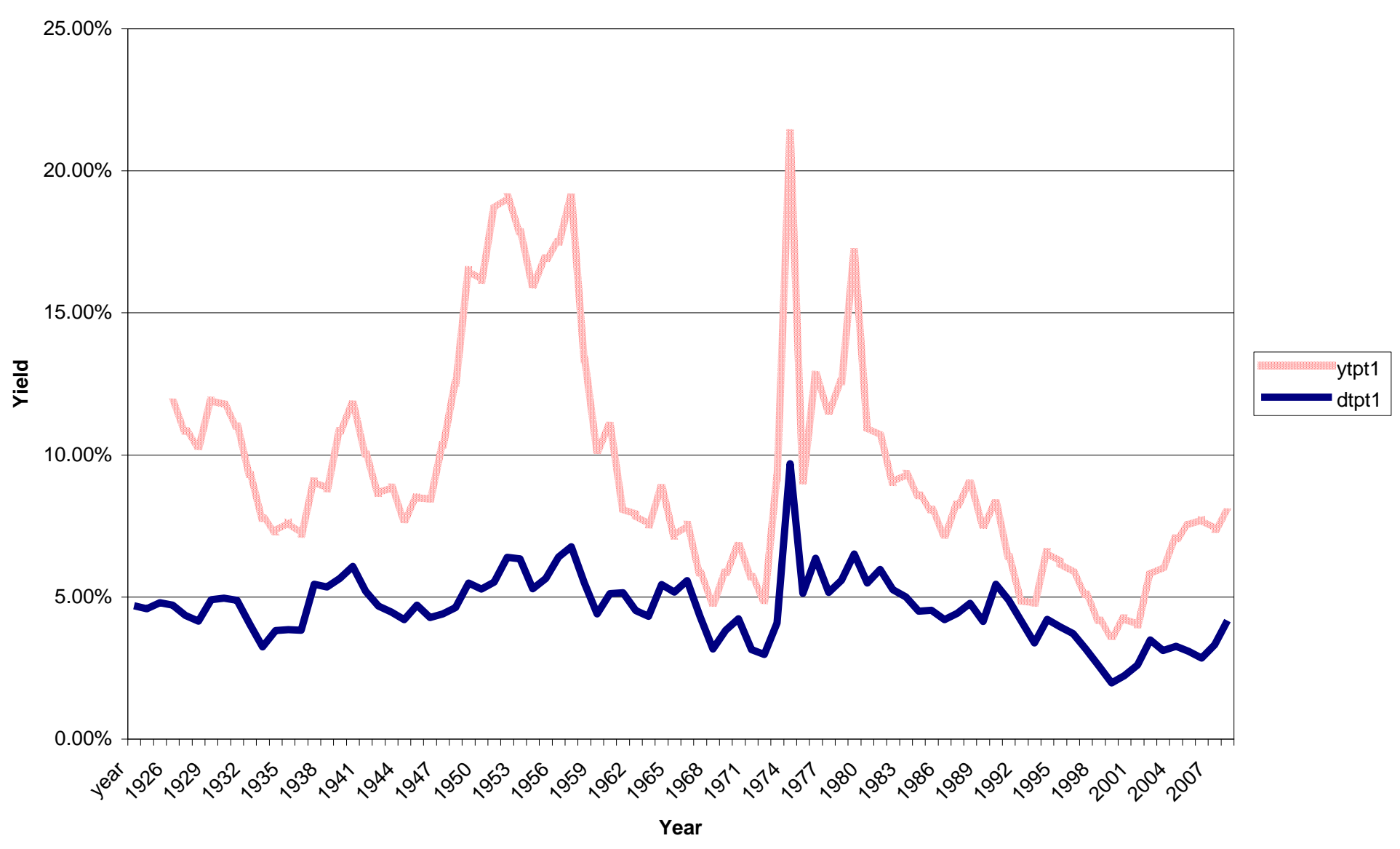


Figure 2: Real Earnings and Real Dividend Growth Rates in UK

Annual growth in dividends and earnings

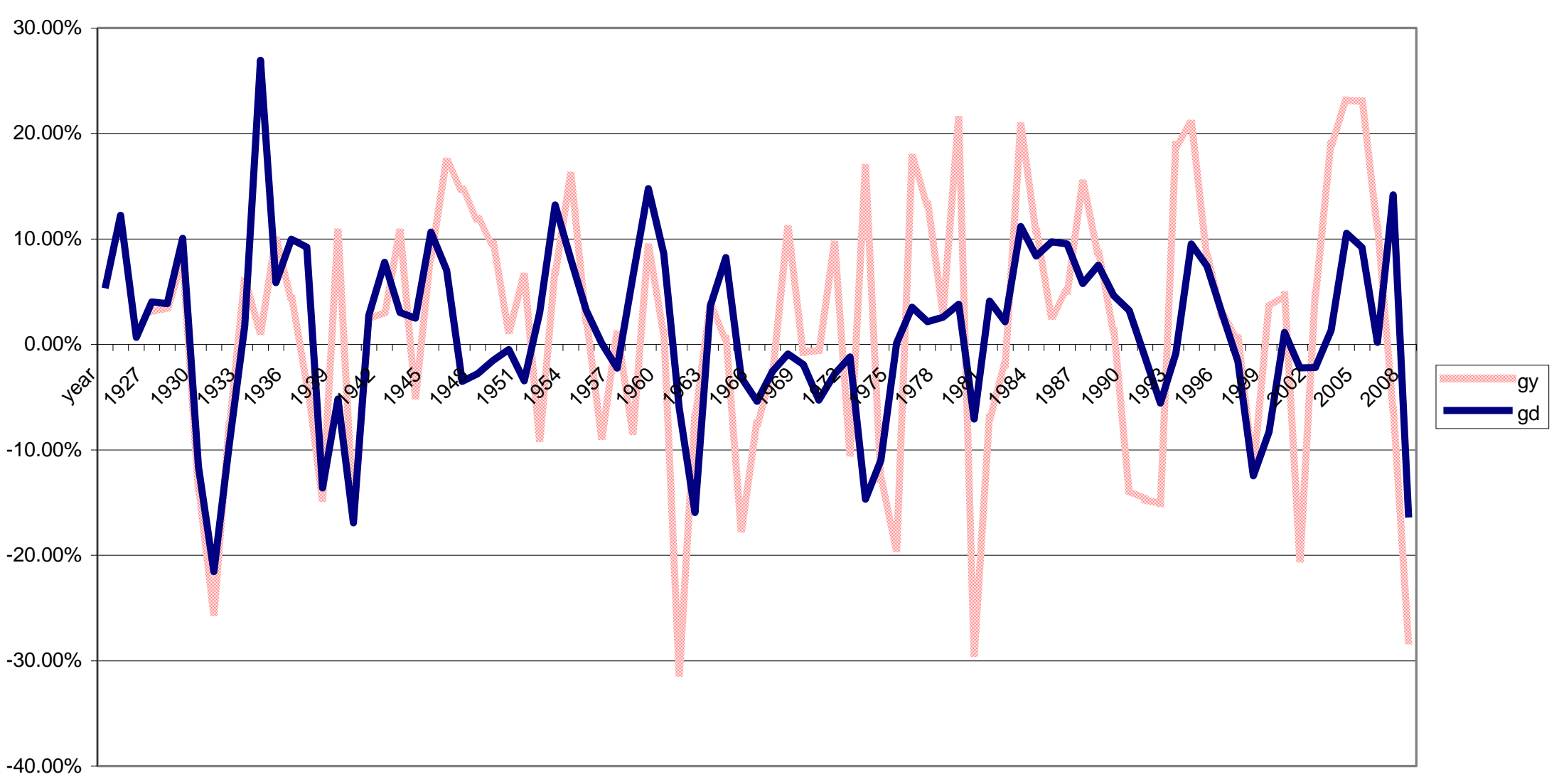


Figure 3: Rolling average 10 year real earnings and Price-ten year average real earnings ratio for UK

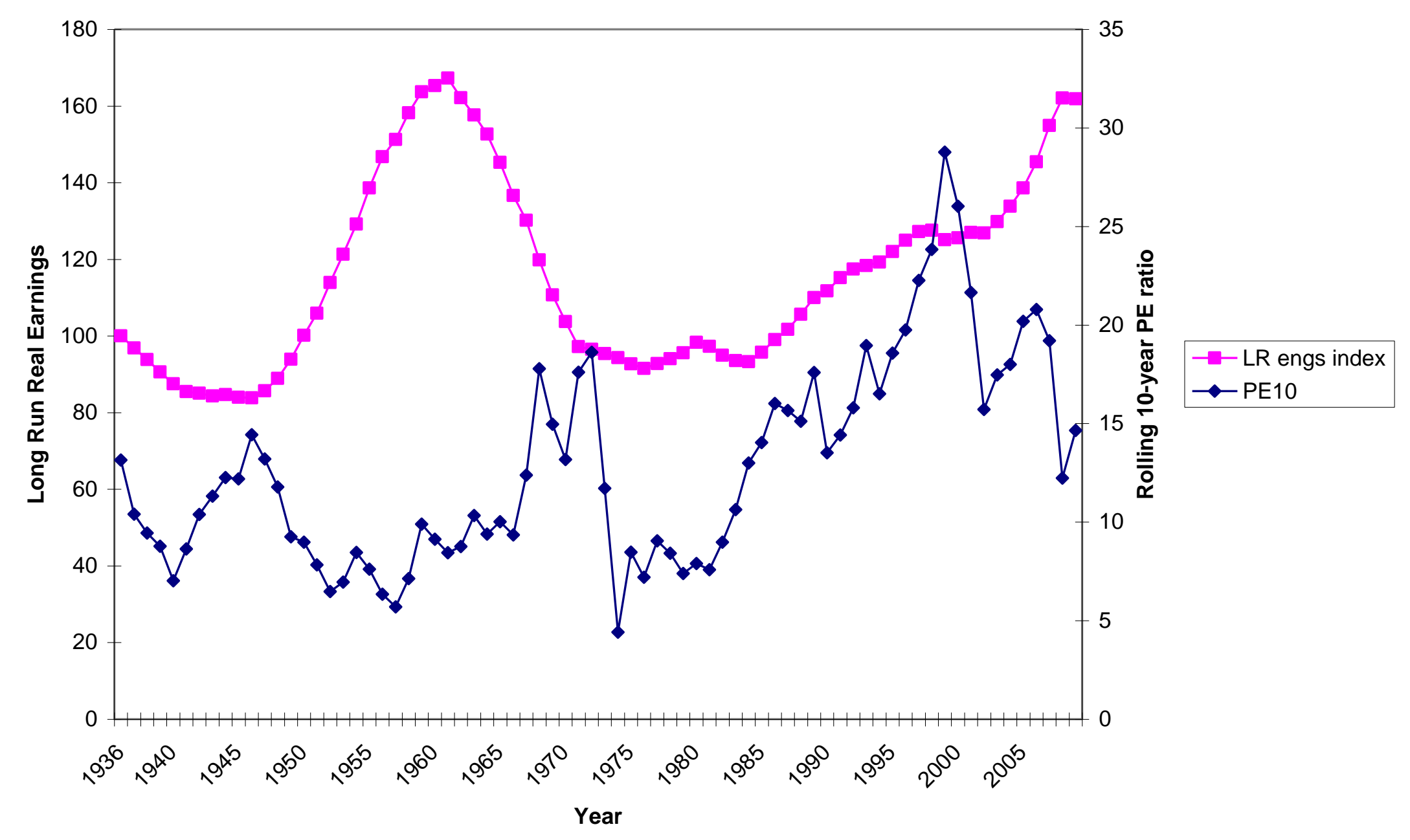


Figure 4: Annual estimates of cost of equity from recursive estimates

Expected cost of equity

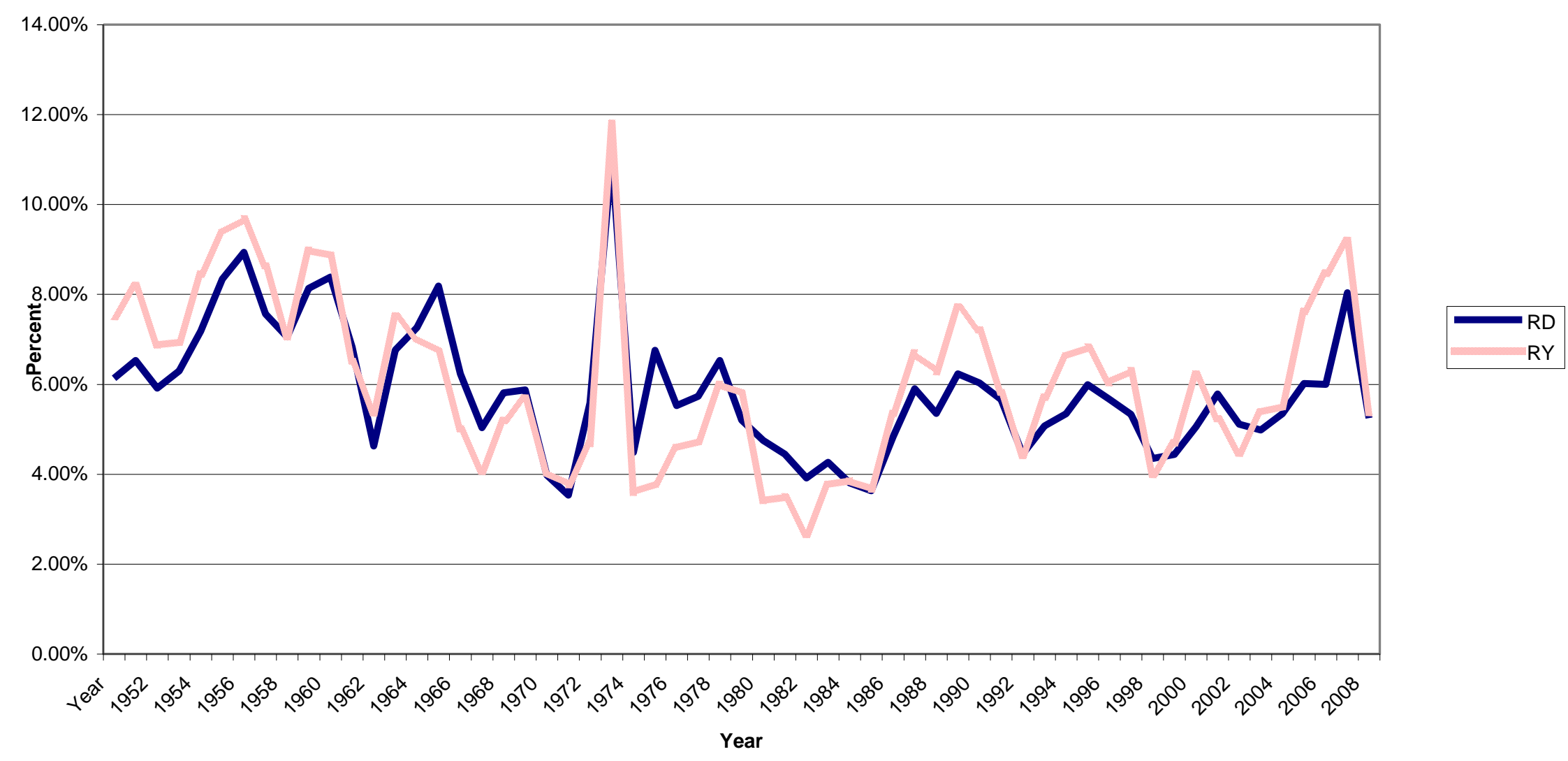

